\title{
The Significant of Food Heritage Endorsement in Building Food Identity
}

\author{
Adilah Md. Ramli ${ }^{1}$, Dg. Khairunisa Ahmad Sapawi ${ }^{1}$, Mohd Salehuddin Mohd Zahari² \\ 1 Faculty of Food Science and Nutrition, \\ Universiti Malaysia Sabah, Kota Kinabalu, 88400, Malaysia. \\ ${ }^{2}$ Faculty of Hotel and Tourism Management, \\ Universiti Teknologi MARA Puncak Alam Campus, Bandar Puncak Alam, 42300, Malaysia. \\ m_adilah@ums.edu.my, khairunisa@ums.edu.my, salehuddinm@uitm.edu.my \\ Tel: 016-8377565 @ 088-320000 (Ext. 8680)
}

\begin{abstract}
Many countries reported having experienced external pressures on their culture and tradition, including losing their food heritage and identity. With that, Malaysia, as a multi-cultural country, is also much concerned in preserving its food heritage and identity. This paper aimed to determine the impact of food heritage endorsement towards building food identity from a food experts perspective. A qualitative approach used to gather information, specifically by using a semi-structured interview with eight informants from government agencies and the food industry. The results revealed that the panel of experts corresponded to the impact of the endorsement of food heritage towards national food heritage in four themes, which were: creating an image; documentation of food heritage; preserving the traditional food; and national identity. The impact of endorsement towards national food heritage would help the nation in building food heritage in the direction of the country's identity, which contributed towards national food identity or national food image. It is not only appreciated among the Malaysians but also in the international arena.
\end{abstract}

Keywords: Impact of endorsement; food heritage; food identity; expert panel

eISSN: 2398-4287 @ 2019. The Authors. Published for AMER ABRA cE-Bs by e-International Publishing House, Ltd., UK. This is an open access article under the CC BYNC-ND license (http://creativecommons.org/licenses/by-nc-nd/4.0/). Peer-review under responsibility of AMER (Association of Malaysian Environment-Behaviour Researchers), ABRA (Association of Behavioural Researchers on Asians) and cE-Bs (Centre for Environment-Behaviour Studies), Faculty of Architecture, Planning \& Surveying, Universiti Teknologi MARA, Malaysia.

DOI: https://doi.org/10.21834/e-bpj.v4i12.1890

\section{Introduction}

Food, cuisine, and culinary traditions are among the most foundational elements of culture. Cuisines are becoming an important part of the contemporary cultural heritage for regions and countries as it is one of the chief symbols of nationalism (Timothy \& Ron, 2013). It also plays a prominent and integral role in the creation, maintenance, and promotion of regional and national identities (Ramshaw, 2016). Other attributes, such as heritage also give an indication and symbol of people's ethnicities, nationalities, and identities (Park, 2009). Heritage, as mentioned above, refers to the intangible cultural heritage. Food is part of the intangible cultural heritage found in traditions, practices, and customs that have become a culture and have been passed down from generation to generation as part of their daily life (Shariff \& Zakaria, 2011). This heritage needs to be preserved and maintained as it is facing homogenising pressures from outsiders (Shariff, Mokhtar, \& Zakaria, 2008).

Heritage, in this study, is insinuated to food heritage. There are several interpretations of food heritage, as mentioned by Ramli et al. $(2013 ; 2014)$ they associate food heritage with agriculture, which consists of pure breed fruits, vegetables, and livestock that are naturally suited to specific regional climates. Additionally, food heritage is associated with using traditional methods of production, such as production techniques, consumption skills, and technology using local produce. The study aims to determine the impact of endorsement of food heritage towards building food identity from the food experts' perspective.

eISSN: 2398-4287 @ 2019. The Authors. Published for AMER ABRA cE-Bs by e-International Publishing House, Ltd., UK. This is an open access article under the CC BYNC-ND license (http://creativecommons.org/licenses/by-nc-nd/4.0). Peer-review under responsibility of AMER (Association of Malaysian Environment-Behaviour Researchers), ABRA (Association of Behavioural Researchers on Asians) and cE-Bs (Centre for Environment-Behaviour Studies), Faculty of Architecture, Planning \& Surveying, Universiti Teknologi MARA, Malaysia. DOI: https://doi.org/10.21834/e-bpj.v4i12.1890 


\subsection{Literature Review}

\subsection{Endorsement of Food Heritage}

Endorsement refers to the gazetting process using an explicit legal requirement in assuring the protection of sites, whether in private or public ownership and creating an explicit legal requirement to assure the protection of the products (Taboroff and Cook, 1994). In this study, endorsement and certification are considered among the preserving methods of food heritage and identity (Bessiere, 1998). For example, the French government decided to publish a list of culinary heritage in the inventory of traditional French treasures funded by the National Council for Culinary Art. There is a diverged interpretation of an endorsement in this context. Berard and Marchenay (2007) and Efthalia and Dimitris (2003) referred to endorsement as the certification of protected designation of origin (PDO), protected geographical indication (PGI), traditional speciality guaranteed (TSG), and products and organic products regulation. These food designation and regulation protect the unique name of products that cannot reproduce in any other place, their reputation, historical links with a given place, and particular characteristics and qualities. Most certified food products can be related to heritage based on their regional and geographical historical association to the place or country (Hui-Tun, 2009). On the other hand, Vasilopoulou, Dilis, and Trichopoulou (2013) have defined endorsement in terms of nutritional claim in traditional food as it is neglected in modern societies undercutting a heritage which has been handed down from generation to generation over many decades or even centuries.

This initiative highlights the awareness and country's determination to preserve and safeguard the culinary heritage by certifying sites for its food throughout the country (Bessiere, 1998). In this context, the key factor in driving the local population to protect their heritage is by cultivating a consciousness of their cultural heritage. Another method is using culinary tourism by promoting awareness and recognition that reflect the understanding of food and cuisines. This represents a central element of the heritages, demonstrating their national cultural characteristics and local features and further developing them into an international brand (Horng \& Tsai, 2012).

Due to the scale of today's globalisation, McCoy (2012) has recognised the need for food heritage to be explored, defined, nurtured, and protected at any cost. According to Alonso and Krajsic (2013), people are experiencing external pressures on their culture and tradition, which include the threat of losing their food heritage or identity in a rapidly changing environment. As the food is usually associated with place and is a ground for individual identity, it must be of the most significant concern in the forming of a heritage area. Moreover, food or food heritage must be protected under a country's legislation or certification in order to promote the country's economy and growth (Tellström, Gustafsson, \& Mossberg, 2006). Endorsing food heritage is beneficial for its authenticity, preservation, awareness, and recognition of the identity of a community or a country (Bessiere, 1998).

Since the heritage protection movement initiate, government awareness has increased on the need to protect history. Various laws, which aim to protect both natural and cultural environments, have been enacted across the world. Several countries have developed heritage protection legislation where culture is featured prominently in the tourism landscape (Timothy, 2011). One of them is Malaysia, which introduced the National Heritage Act in 2005 for managing and preserving national culture and heritage and acting as a mechanism for image and revenue through domestic and international tourism (Mohamed, 2005).

\subsection{Food Identity}

Food holds the key to any culture. People generally make assumptions about other people's diet based on whom they claim to be and about whom other people are, as it based on what they eat (Counihan \& Van Esterik, 2012). Ruark (1999) have claimed that food is one of the most common markers of identity, but added that people tend to overlook the power of food despite its routine inclusion in one's daily life.

Scholars agreed that cross-culturing among the ethnic groups through acculturation, assimilation, and adaptation processes would gradually create or form food identity in multi-cultural countries (Fox \& Ward, 2008; Ramli et al., 2016). Furthermore, certification of heritage and traditional food, in the long run, can strengthen the national food identity formation (Manaf, 2008). DeSoucey (2010) has also claimed that the gazetting of gastronomic heritage significantly establishes the national food cultural identity.

\subsection{The Impact of Endorsement towards Building Food Identity}

Several adverse effects on social and cultural impacts identified by Timothy (2011), such as different use of social space, cultural change, cultural commodification, cultural theft, forced displacement, and disharmonious resident-tourist or destination-tourism relations. However, there are also positive social impacts in which tourism contributes to social and cultural well-being, for instance, the revival of lost or declining elements in culture, societal esteem, nurturing of traditional art forms, and the creation of new art forms without detracting from traditions. It also helps to create jobs and taxes and stimulates entrepreneurialism in heritage destinations (Timothy, 2011). Ramshaw (2016) has stated that there is a solid and enduring relationship between heritage and cuisine. Based on the literature mentioned above, there is a lack of literature review showing the outcome of endorsing food heritage to become the national heritage to contribute toward nation-building, especially from the professional bodies' perspective. Therefore, the study's findings and the outcome are to contribute to the bodies of knowledge on national food heritage.

\subsection{Methodology}

\subsection{Research Design}

A qualitative approach is used to gather the required information using semi-structured interview conduct with the relevant authorities that are closely involved with the endorsement of Malaysian food heritage. The semi-structured interview comprises of eight questions 
that divided into five sections, which contain background, introduction, determinant criteria for food heritage, procedure, and authority responsible for national food heritage list and food preservation, and lastly, food identity formation. It is instructive to note that duallanguage of Bahasa Malaysia and English used for the study's instrument as both commonly communicated in Malaysian government bodies and agencies. All the questions developed and adapted from Guerrero et al. (2009); Hergesell (2006); Lin, Pearson, and Cai (2011) and McDonald (2011). The interview questions were reviewed and finalised by an expert panel with the necessary alterations made based on their suggestions as illustrated in Table 1

Table 1: The interview question

\begin{tabular}{ll}
\hline No. & Questions \\
\hline 1. & How do you define food heritage? \\
2. & What are the determinants criteria in selecting traditional food as food heritage? \\
3. & What is the main purpose for certain dishes or food included in the heritage list or gazetted? \\
4. & Who is responsible for endorsing and suggesting the food heritage list? \\
5 & How effectively does the endorsement of food heritage toward preservation? \\
6. & What are the impacts on the endorsement of food heritage towards national food identity?
\end{tabular}

Before the interview conducted, a pilot interview or also known as preliminary information gathering executed with two ex-appointed panels which had involved in the endorsement process of the national food heritage at the National Heritage Department of Malaysia. The interview intended to determine the appropriateness of a list of semi-structured questions developed before the actual interview session. The two panels are interviewed in separate sessions. Their comments and recommendations considered and incorporated into the semi-structured interview question draft. Subsequently to this, five academicians and non-academicians with food background and knowledge approached to check on the questions' clarity and understandability before derived into the final version of this qualitative instrument.

About qualitative sample, Merriam (2009) stated that there is an ambiguity in determining the sample size, as it depends on a list of questions, the type of data gathering method, analysis, and the researcher's resources that support the study. By the same token, Patton (2002) explained that qualitative researchers are not bound by any specific rules in determining the sample size for the study. The sample size depended on what the researcher wishes to know, the purpose of the inquiry, the usefulness of the information, the credibility of the information, and the possible outcome with the available time and resources. However, several researchers recommended specific sample sizes such as Boyd (2000) who regarded two to ten participants or research subjects as sufficient to reach saturation, and Berg (2004) who recommended that it is sufficient to have five to twenty key informants for the qualitative study approach. Creswell (1998) recommended 'long interviews with up to ten people' for a phenomenological study. Based on these notations, fifteen expert panels from the committee appointed by the National Heritage Department (NDH) chosen for the interview. The expert panels are responsible for the endorsement and certification of the nation's food heritage and are deemed well knowledgeable on the field.

The potential informants for the qualitative method were from government agencies and food industry experts who have been appointed as committee members from 2009 until 2014 by Jabatan Warisan Negara (National Heritage Department). The contextual setting for qualitative data collection for this study is the National Heritage Department located in Kuala Lumpur. The department is responsible for the endorsement and certification of the nation's food heritage with fifteen expert panels appointed as a committee. The panels selected from various agencies ranging from the executive director of heritage, heritage officers, the museum representative, food professionals (e.g., chef and food writer), and academicians (table 2).

Table 2: The Appointed Panels

\begin{tabular}{lll}
\hline No. & Panel & Identified \\
\hline 1. & Government Agencies representative & 6 \\
2. & Professional (chef /food writer) & 7 \\
3. & Academician & 2 \\
\hline
\end{tabular}

With permission received from the Commissioner of Heritage of National Heritage Department (NHD), all the fifteen experts personally contact to acquire their willingness to participate in this study. The study's aim, the researcher's details, and the purpose of the interview highlighted during the conversation. From the 15 expert panels that identified, seven of the panels are unable to commit, while others have agreed to be the participants. The dates, times and venues for the interviews are then arranged based on the convenience and wishes of the panels, which require the unlimited flexibility on the researcher's part.

All documentation and communication through electronic and paper media used to gain the informants' approval for the interview. All the interviews are tape-recorded, and each session lasts around forty minutes to an hour. The researcher has brought a moderator in some of the interviews session, which allows the researcher to observe the interview processes. During the interview, a predetermined set of structured questions based on the objectives of the study posed to the panel. The researcher ensures not ask questions which can lead to greater biased answers obtain from the panel. All the interview sessions successfully were undertaken with the cooperation and full commitment of the panels. The information obtains through the successful interview is then transcribed and translated into English, and is sent back to the panels for verification and approval on its transcription accuracy. The returned transcript is, furthermore, rechecked by the researcher for any information discrepancies. In the next step, the transcript of the interview information is coded and analysed using thematic analysis. The findings further explained in the analysis section. 


\subsection{Measurement}

In the qualitative method, the data from the interview are transcribed and transformed into a three-step process using categorisation, coding, and evaluation as analytical tools. Transcribed interviews categorised using a scheme of emerged categories, allowing the contents to be systemically verified (Tellstrom et al., 2006). The codes identified as a theme using an inductive categorisation method to identify the suitable variables used for the constructs. Inductive categorisation involves a classification of recurring themes found in a text passage (Bogdan \& Biklen, 1992; Merriam, 2002; Spiggle, 1994). Under each theme, the interviews are coded and categorised for further analysis using a thematic analysis before the results reported. The transcribed information categorised using Atlas.ti software. The transcriptions analysed using the coding system. Coding is the process of assigning meaningful numerical values that facilitate the understanding of the data. The purpose of coding is to enable the researcher to simplify and focus on the essential characteristics of the data (Hair et al., 2007). Furthermore, coding analyses is to identify emerging themes from the open-ended responses from the interviews (Spiggle, 1994).

The validity and reliability of the qualitative data analysis is the degree of consistency in the assignment of similar words, phrases or other kind of data to the same pattern or theme by different researchers. It referred to as inter-rater reliability. Reliability can also be a mean for the degree of consistency that the same researcher assigns similar observations and interpretations at different points in time. Validation in qualitative research is the extent to which qualitative findings accurately represent the phenomena. The trustworthiness of the data depends on the integrity and honesty of the research (Polkinghorne, 2005). Besides that, Lincoln and Guba (1985) have emphasised "inquiry audit" as one measure that may enhance the dependability of qualitative research. In order to enhance the credibility and trustworthiness of the research data, besides adapting explicit methodology and a data collection method (Hussey \& Hussey, 1997), the credibility and trustworthiness on qualitative information are generally applied through peer checking (using an experienced colleague to re-analyse some of the data) as ways of ensuring that the data has been analysed correctly (Freshwater \& Rolfe, 2004). From all of the methods mentioned, the member checking method applied in this research, whereby the research findings and analysis informally send to the informers for verification and agreement.

\subsection{Findings and Discussion}

\subsection{Informant Profile}

Eight informants are involved in the interview selected from the list of food experts committee who have been appointed by Jabatan Warisan Negara. All informants are male, in the age range of 34-40 years and 45-60 years old. Their education backgrounds consist of Diploma, Bachelor's Degree, Master, and PhD levels, while their involvement in the field of food is more than five years. Their current work profession includes academic and government agencies.

\subsection{Qualitative Findings}

The informants were asked about the impact of the endorsement of food heritage towards national food heritage. The findings showed that the panel of experts was able to produce some relevant information pertaining to the issue at hand. After sorting through the information obtained, four recurring themes are identified: a) Creating an image; b) Documentation of food heritage; c) Preserving traditional food, and d) National identity.

\section{i. Creating an Image}

Food applies to time, place, and memory, as well as a form of edible chronotopes (sensory space-time convergences). Therefore, food is one of the most powerful symbols of a community and even a nation (Turgeon-Gouin, 2011). It is also a defining social marker where it can create a symbol projecting an image or reinforcing a self-image (Harrington \& Ottenbacher, 2010). Within academic research, several studies focusing on food with destination development, image, identity formation, and sustainability have been undertaken (Backe, 2013; Dupree, 2002; Everett, 2016; Hjalager \& Corigliano, 2000; Sunanta, 2005).

Aligned with the above statement, nearly all experts in the panel mentioned image as one of the outcomes of food heritage endorsement. Panel Two has stated that food heritage symbolised a country's image and contributed as one of its tourism destination attractions. This indirectly promotes the country's image to tourists. Panel Five has shared similar views in which he states that image could also be promoted through electronic media such as national television (e.g. RTM), preferably via food heritage documentaries. Other than that, it is also potentially served as a brand name that can be related to a particular country, as mentioned by Panel Eight. Panel Eight states that an endorsement can provide a substantial impact on the perception of the country's image in the long term. Below are some of the experts' quotations (refer to Table 3).

\section{Table 3: Creating an Image}

\section{Quotation}

Panel 2 "... soon I see that heritage food will represent an image of the country. The country needs to utilise heritage food in promoting and attracting tourists through positive association with destination and country image. In the long run, heritage food will become a part of the country's image, and it will boost the [nation's] self-esteem and serve as [a] positive image to children and youths and slowly contribute towards the formation of national food identity..."

Panel 5 "...so I would say yes, why not we promote it if it can contribute towards the national food identity. We have someone who is not only capable of preparing the dishes authentically but also possesses the knowledge regarding food heritage. Some effort needs to be [done] to present the image on television; maybe we can showcase food heritage in RTM (Radio Televisyen Malaysia) as a food heritage documentary..." 
Panel 8 "... it gives the brand name to the country the moment people see it. They know that [a] certain food is associated or belongs to a certain country even if other countries try to imitate the dish. So, the endorsement, in reality, is a long-term strategy to establish a brand name. Eventually, it will create a strong impact of portraying the country's image based on the food heritage that has been gazetted. In other words, we are also advertising to the world about the food that is authentically available only in this country..."

\section{ii. Documentation of Food Heritage}

The need to create public awareness and knowledge regarding the existence of national food heritage is imperative as it is recognised as one of the nation's identities (Aziz, Mat, \& Halim, 2008; Bessiere, 1998; Du Cros, 2009; Han, 2001; Sayej, 2010). An example can be seen in France when the government decided to publish a list of the culinary heritage in the inventory of traditional French treasures funded by the National Council for Culinary Art. This initiative highlights the awareness and determination of the country to preserve and safeguard the culinary heritage by certifying sites for their food throughout the country (Bessiere, 1998).

Consistent with the above statements, most of the experts have stated that in the effort to create awareness on food heritage, it is essential to have proper documentation materials on food heritage, which include cookbooks or recipes that are related to the history and cultural background of the dishes. In the same token, Panel Two suggests that every state has to play a role in maintaining documentation of their food heritage. A good starting point is through the documentation of cookbooks and authentic recipes to particular states. This is reaffirmed by Panels Six and Seven as they have stated the need to have local people to manage the documentation, especially in identifying specific ingredients, cooking methods, and preparation. Additionally, most of the existing cookbooks related to traditional food are written by foreigners who may either have different views on the local food and culture or have modified existing recipes to suit their preferences in taste, presentation or preparation method. Below are some of the Panels' excerpts (refer to Table 4).

Table 4: Documentation of Food Heritage

$$
\text { Quotation }
$$

Panel 2 ".. I think every state has to play [its] role as in every state, there is a cultural department and in Johor specifically, they already have their own heritage foundation, so they have produced cookbooks and recipes. The only real problem [that] needs to be addressed is the lack of background information regarding the food. There is no problem regarding recipes from all states, including traditional recipes, but in the sense of information, we miss out in the history and philosophy. That is a challenge that requires attention..."

Panel 6 "...detailed studies related to the writing, menu preparation, own cookbook, and particular ingredients preparation should be done by a person who is a major in the related study, and it does not have to be of a particular race. The last time some foreigners made them for us, and we made theirs, and we did not withhold them to our own community, but it is good if our own community can conduct the study. I am hoping that there are a lot of studies conducted pertaining to our customs. Our community has also undertaken less specific studies, which are related to the local gastronomy knowledge such as how to prepare it, how to maintain the taste, time of preparation, and how to control the heat. Studies on the background history have [also] been done, but it is not as detailed and systematic. [Nowadays], people are using technology to their advantage, you just need to press a button, and everything else is taken care of, including the production of specific taste..."

Panel $7 \quad$ "... Yes... when we see the dishes or traditional food, generally the list that we have is not complete. We need to list down additional food that has been inherited [from] generation to generation or traditional dishes that fulfil the criteria to be listed as food heritage. Due to the lack of literature about the existing food, there is limited information on the dishes available, but it is fortunate that the dishes or food that may be included in the list of heritage possess high cultural value..."

\section{iii. Preserving Traditional Food}

Traditional cuisine is one of the best examples of food heritage that covers the unique aspects of a particular culture in terms of the ingredients, preparation methods, dishes, or services of foods. This type of cultural heritage is more challenging to preserve as compared to physical objects as it concerns the values, beliefs, behaviours and rules of the society that are difficult to measure, especially among the public (Shariff et al., 2008). In line with this statement, it is evident that the difficulty in preserving cultural heritage is greater concerning intangible heritage, such as traditional food. Hence, it emphasises the importance to endorse traditional food, as it would help to preserve and safeguard it from being lost, stolen or tampered with, for the younger generation.

This matter is confirmed by Panel Three, whereby food endorsed as heritage guarded against being tampered with or imitated by other people or countries. Indirectly, it preserves the authenticity of the food in the long run. On the same note, Panel-Seven has stated that the endorsement should cover all traditional ethnic dishes that can be considered as heritage. Since some dishes are rarely cooked and can only be found during a particular celebration or festival such as Gawai festival, some of these dishes are unable to be replicated or prepared as there is none from the older generation who can teach the foods' preparation methods. Below are some of the Panels' excerpts (refer to Table 5).

\section{Table 5: Preserving Traditional Food}

\section{Quotation}

Panel 3 "... yes, if we look at the first one, it is able to safeguard the food from being tampered [with]. It is just that actually here they are selling imitations that have been tampered [with]. What I mean is that they sell imitation products with the same name but using different ingredients. Then, the other one is preserving the authenticity of our heritage, which simply means that it can at least preserve the authenticity that we have. Yes, in this case, it is over the long-term run..."

Panel $7 \quad$ "... in general, we have [a] list of a hundred or even a few hundred food items up until now. I think it is still not enough and we still need to put as many as possible so that we do not leave behind any dishes that are equally valuable from being included [as] traditional or heritage food. That should be the case because there are certain dishes that people only have ever heard, but never seen. For instance, I am in my community, and there are dishes mentioned during [the] Gawai festival, but now when we ask about the food, nobody knows how to make, it is no longer in my community..." 


\section{iv. National Identity}

Timothy and Ron (2013) have stated that food heritage is a marker of identity and one of the ways to preserve it is by promoting food as national patriotism, familial, regional patrimony, and agricultural tradition. One clear example can be seen through traditional Serrano cheese as a local Brazilian product with a strong food heritage (Vitrolles, 2011). Besides, food is used as a vehicle of national identity owing to its power and resources of cultural, political, and economic identities as they are shaped by institutional protections (DeSoucey, 2010).

In agreement with the above statements, the impact of endorsing food heritage includes building a nation's identity that comprises custom, culture, and cuisine as they symbolise the history of a country. Furthermore, Panel Three has stated that if the country does not endorse for food heritage, the dire consequence would be the loss of the country's cultural identity, specifically on the originality of the traditional food knowledge that could not be transferred to the next generation. By endorsing food heritage, it creates a brand that differentiates one country to another which, in the long term, creates a country's identity that is recognised globally. Below are some of the Panels' citations (refer to Table 6).

Table6: National Identity Quotation

Panel 2 "... when there is this object (national heritage), we will know that the food items belong to our country, we will know where we are. That is the reason why the heritage department is created, to collect and conduct research about food, about custom as these things are our identity and we hold on to them and many more. [This is because] in all countries, all the people of the world will return to their motherland. They would look for originality so that we will have a country, identity, pride, and so on..."

Panel 3 ".... If we [lose] food heritage, we are going to lose our culture, and most importantly, our identity. If we do not have the skill to prepare the dishes, we do not eat our own food, so we just lose another precious thing. We are going to lose parts of our culture, and there is nothing we can share with the future generation. Every day is going to be the same if we do not have our original identity..."

Panel 8 "... however, food heritage is one of the ways to expose and promote the country to the world as we are the source of food authenticity in this respect. Nobody has done more or less like what they called food heritage, and maybe it is because I am not in the field of food industry. But I notice, many countries like Japan, for instance, they have sushi, and Korea, they have their own special food. They associate this food with their own country as what you see in Malaysia; if we are to become the heritage and also promote Malaysia..."

The finding on the impact of the endorsement of food heritage towards national food heritage can be transformed into a diagram (figure 1).

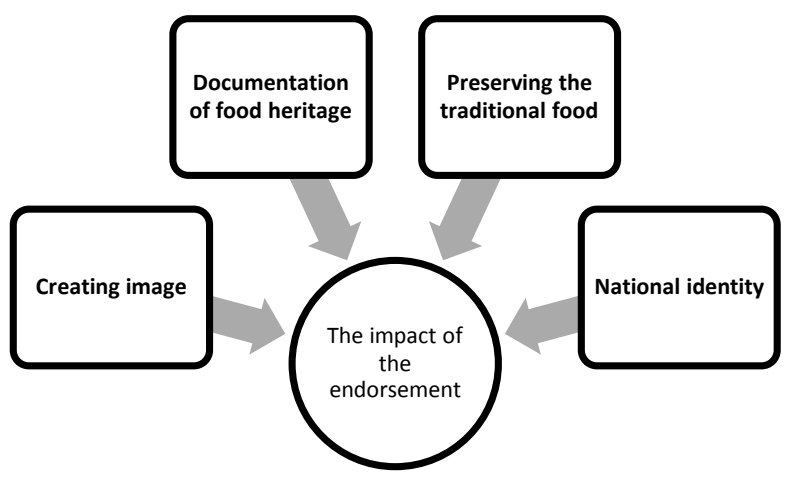

Figure 1 The impact of the endorsement of Food Heritage

\subsection{Conclusion and Limitation}

In this study, a panel of experts have corresponded to the impacts of food heritage endorsement toward national food heritage in four themes: creating an image; documentation of food heritage; preserving traditional food; and national identity. The valuable information received from the expert panel deals with the purpose of food heritage included in the heritage list, the authority that contributes to the endorsement of food heritage and the impact of endorsement of food heritage. Nevertheless, there is a lack of information, especially regarding the primary purpose for a dishes to be in the heritage list. During the interview that the primary purpose for the inclusion is more towards preserving and sustaining the traditional food itself for it to become an image or identity of a country.

The government agency and food experts are responsible for the endorsement of food heritage, as aligned with the National Heritage Act 2009. In answering the question of the effectiveness of the endorsement of food heritage towards preservation, it is revealed from the interview that positive response is received especially in creating awareness among the public, and the food itself can be commercialised. It is hoped that this study will help to extend the existing literature and create a new body of knowledge, particularly in Malaysia. Recognising the impact of endorsement towards national food heritage will help the nation in building food heritage towards the country's identity, which will, in the long run, contribute towards national food identity or national food image that is appreciated not only among the Malaysians but also in the international arena. 
In terms of the limitation of the study, first of all, there was a lack of information on the literature from experts on the impact of endorsement of food heritage towards national food heritage. Based on the available lists issued by the National Heritage Department of Malaysia, there are more than two hundred types of food to date that have been classified and gazetted as the national food heritage. By looking at the list, most of the foods, however, come from the major ethnic groups in this country as of Malay, Chinese and Indian with only a few foods come from other minorities. This number is, in fact, still small in comparison to the vast treasures of traditional foods belonging to dominant ethnic groups as well as the minorities in Malaysia. Nevertheless, as endorsement and certification of food heritage will directly benefit all generations, ethnics communities and nation as a whole, the efforts being put by the Department of National Heritage to classify traditional food that meet the stipulated food heritage criteria must aggressively be done. Also, minority ethnics groups shall be put into extra focus as to provide broader spectrum on Malaysia's food heritage. The study is, however, limited due to the ability to secure a small number of samples which is eight experts for the interview. For future similar research, it is suggested to obtain more experts for the interview as these experts are committee from various industries, agencies, and academicians that can provide different perspectives and inputs regarding this matter.

\section{References}

Alonso, A. D. (2013). Tannat: The Positioning Of A Wine Grape As Symbol And 'Referent' of A Nation's Gastronomic Heritage. Journal of Heritage Tourism, 8(2-3), 105119 .

Aziz, W. A. W. A., Mat, A. C., \& Halim, M. A. S. A. (2008). Semiotic Knowledge Towards Heritage Product in Tourism Industry: A Case of Terengganu. Paper presented at the Thrusting Islam, Knowledge and Professionalism in ECER Developmen, 1st ECER Regional Conference (ERC) 2008, Renaissance Hotel, Kota Bharu, Kelantan, Malaysia.

Backe, J. O. (2013). Culinary Networks and Rural Tourism Development: Constructing the Local Through Everyday Practices. In C. M. Hall \& S. Gossling (Eds.), Sustainable Culinary System: Local Foods, Innovation, Tourism and Hospitality (pp. 47-63). New York: Routledge

Bessiere, J. (1998). Local Development and Heritage: Traditional Food and Cuisine as Tourist Attractions in Rural Areas. Sociologia Ruralis, 38(21-34).

Berard, L., \& Marchenay, P. (2007). Localized products in France: definition, protection and value-adding. Anthropology of food (2). http://aof.revues.org/415

Berg, B. L. (2004). Qualitative Research Methods For The Social Sciences: Pearson Boston.

Boyd, S. M. (2000). Cultural Adaptation and Identity Formation: The Transcultural Journey and Identity Reformation of Four Canadian Teachers Returning From a Sojourn to Japan (Master), York University, ProQuest Dissertations and Theses (PQDT).

Bogdan, R. C., \& Biklen, S. K. (1992). Qualitative Research: An Introduction To Theory And Methods. Needham Height: Allyn \& Bacon.

Creswell, J. W. (1998). Qualitative Inquiry And Research Design: Choosing Among Five Designs: Thousand Oaks, CA: Sage.

Counihan, C., \& Van Esterik, P. (Eds.). (2012). Food and culture: A reader. Routledge.

DeSoucey, M. (2010). Gastronationalism: Food Traditions and Authenticity Politics in the European Union. American Sociological Review, 75(3), 432-455.

Du Cros, H. (2009). Emerging Issues For Cultural Tourism In Macau. Journal of Current Chinese Affairs, 38(1).

Efthalia, D., \& Dimitris, S. (2003). Consumer Evaluations Of Product Certification, Geographic Association And Traceability In Greece. European journal of Marketing, $37(5), 690-705$.

Everett, S. (2016). Iconic Cuisines, Marketing And Place Promotion. In D. J. Timothy (Ed.), Heritage Cuisines: Traditions, Identities and Tourism (pp. 119). New York: Routledge: Taylor \& Francis Group.

Fox, N., \& Ward, K. J. (2008). You Are What You Eat? Vegetarianism, Health And Identity. Social Science \& Medicine, 66(12), 2585-2595.

Freshwater, D., \& Rolfe, G. (2004). Deconstructing Evidence-Based Practice: Routledge.

Guerrero, L., Guardia, M. D., Xicola, J., Verbeke, W., Vanhonacker, F., Zakowska-Biemans, S., . . Hersleth, M. (2009). Consumer-Driven Definition Of Traditional Food Products And Innovation In Traditional Foods. A Qualitative Cross-Cultural Study. Appetite, 52, 345-354.

Han, S. (2001). Cultural Heritage Management in South Korea. (Doctor of Philosophy), University of Minnesota, ProQuest Dissertations \& Theses Globa. Retrieved from http://search.proquest.com.

Hair, J. F., Money, A. H., Samouel, P., \& Page, M. (2007). Research Methods for Business. USA: John Wiley \& Sons, Ltd.

Harrington, R. J., \& Ottenbacher, M. C. (2010). Culinary Tourism—A Case Study of the Gastronomic Capital. Journal of Culinary Science \& Technology, 8(1), 14-32.

Hergesell, A. (2006). Influence Of The World Heritage Certification On Destination Choice. (Master of Arts), Bournemouth University.

Hui-Tun, C. (2009). The Rise of Culinary Tourism and Its Transformation of Food Cultures: The National Cuisine of Taiwan. Copenhagen Journal of Asian Studies, 27(2), 84-108. 
Horng, J. S., \& Tsai, C. T. S. (2012). Culinary Tourism Strategic Development: An Asia-Pacific Perspective. International Journal of Tourism Research, 14(1), 40-55. Hjalager, A.-M., \& Corigliano, M. A. (2000). Food For Tourists—Determinants Of An Image. International Journal of Tourism Research, 2(4), 281-293.

Hussey, J., \& Hussey, R. (1997). Business Research. A Practical Guide For Undergraduate And Postgraduate Students

Lin, Y.-C., Pearson, T. E., \& Cai, L. A. (2011). Food As A Form Of Destination Identity: A Tourism Destination Brand Perspective. Tourism and Hospitality Research, 11(1), 30-48.

Lincoln, Y. S. \& Guba, E. G. (1985). Naturalistic Inquiry (Vol. 75): Sage.

Manaf, Z. A. (2008). Establishing The National Digital Cultural Heritage Repository In Malaysia. Library Review, 57(7), 537-548.

McCoy, L. (2012). Food Heritage Planning Proposals: Planning For Food Heritage Celebrations In Central Virginia. Retrieved from http://www.virginia.edu

McDonald, H. (2011). Understanding The Antecedents To Public Interest And Engagement With Heritage. European journal of Marketing, 45(5), 780-804.

Merriam, S. B. (2002). Introduction To Qualitative Research Qualitative Research In Practice: Examples For Discussion And Analysis (pp. 3-17). San Francisco: JosseyBass

Merriam, S. B. (2009). Qualitative Research: A Guide to Design and Implementation. USA: John Wiley \& Sons, Inc.

Mohamed, B. (2005). Cultural Tourism Promotion And Policy In Malaysia. Paper presented at the Korea, Japan, China, Philippine, Spain, Turkey, India \& USA Joint World Cultural Tourism Kyung-Hee University, Seoul, Korea.

Patton, M. Q. (2002). Two Decades Of Developments In Qualitative Inquiry A Personal, Experiential Perspective. Qualitative social work, 1(3), 261-283 Polkinghorne, D. E. (2005). Language And Meaning: Data Collection In Qualitative Research. Journal of counseling psychology, 52(2), 137.

Ramshaw, G. (2016). Food, Heritage and Nationalism. In D. J. Timothy (Ed.), Heritage Cuisine: Traditions, Identities and Tourism (pp. 54-62): Taylor \& Francis.

Ramli, A. M., Zahari, M. S. M., Halim, N. A., \& Aris, M. H. M. (2016). The knowledge of food heritage Identity in Klang Valley, Malaysia. Procedia-Social and Behavioral Sciences, 222, 518-527.

Ramli, A. M., Zahari, M. S. M., \& Talib, S. A. (2014). Identification of Food Heritage: Food Identity Analysis on Demographic Background. In National Research \& Innovation Conference for the Graduate Students in Social Sciences.

Ramli, A., Zahari, M. M., Ishak, N., \& Sharif, M. M. (2013). Food heritage and nation food identity formation. Hospitality and Tourism: Synergizing Creativity and Innovation in Research, 407.

Ruark, J. K. (1999). A Place at the Table. Chronicle of Higher Education, 9.

Sayej, G. J. (2010). Palestinian Archaeology: Knowledge, Awareness and Cultural Heritage. Present Pasts, 2(1).

Shariff, N. M., \& Zakaria, Z. (2011). Digital Mapping of Intangible Cultural Heritage: The Case of Traditional Foods. International Journal of the Humanities, 8(11), 69-74.

Shariff, N. M., Mokhtar, K., \& Zakaria, Z. (2008). Issues in the Preservation of Traditional Cuisines: A Case Study in Northern Malaysia. International Journal of the Humanities, 6(6), 101-106.

Sunanta, S. (2005). The Globalization Of Thai Cuisine. Paper presented at the Canadian Council for Southeast Asian Studies Conference, York University, Toronto.

Spiggle, S. (1994). Analysis And Interpretation Of Qualitative Data In Consumer Research. Journal of consumer research, 21(3), 491-503.

Taboroff, J., \& Cook, C. C. (1994). Cultural Property Conservation and the Development Process: The World Bank Group.

Tellström, R., Gustafsson, I.-B., \& Mossberg, L. (2006). Consuming Heritage: The Use Of Local Food Culture In Branding. Place Branding, 2(2), 130-143.

Timothy, D. J., \& Ron, A. S. (2013). Understanding Heritage Cuisines And Tourism: Identity, Image, Authenticity, And Change. Journal of Heritage Tourism, 8(2-3), 99104.

Timothy, D. J. (2011). Cultural Heritage and Tourism: An Introduction. Bristol: Charlesworth Press.

Turgeon-Gouin, C. (2011). The Myth Of Quebec's Traditional Cuisine. (M.A. MR75957), McGill University (Canada), Canada. Retrieved from http://search.proquest.com. ProQuest Dissertations \& Theses (PQDT) database.

Vasilopoulou, E., Dilis, V., \& Trichopoulou, A. (2013). Nutrition Claims: A Potentially Important Tool For The Endorsement Of Greek Mediterranean.

Vitrolles, D. (2011). When Geographical Indication Conflicts With Food Heritage Protection, retrieved 9 December 2012, from Anthropology of food http://aof.revues.org/6809 